\title{
Distance Optimization for Darrieus VAWT arrangement in a wind farm
}

\author{
Amir Ali Al-batal ${ }^{1}$, M.H. Mohamed ${ }^{2}$, S. Shaaban ${ }^{3}$ \\ ${ }^{1,3}$ mechanical engineering department,Arab Academy for Science, Technology \& Maritime Transport, Cairo, \\ Egypt- ${ }^{2}$ Renewable Energy Lab. of Mechanical Power Engineering Dept., Faculty of Engineering, Mattaria, \\ Helwan University, Cairo, Egypt
}

\begin{abstract}
From the beginning of the civilization the human race strives for methods to get energy from. Wind energy was one of the earliest energy sources have been used by the human being. In the recent years the need for clean energy has been raised due to the Global Warming of earth, therefore the wind energy has been introduced as a key player in the field of clean renewable energy and alternative to the fossil fuel. There are two main types of wind turbines, one that rotates around the horizontal axis parallel to the ground which is more common horizontal axis wind turbine (HAWT) and the one which rotates around vertical axis to the ground vertical axis wind turbine (VAWT).The present work aims to study numerically the effect of farming of $3 \mathrm{H}$ rotor each have 3 blades in equilateral triangle farm-like configuration on the each of them, comparing the final performance to one of them when it's alone in the field using Computational Fluid Dynamics.
\end{abstract}

\section{INTRODUCTION}

From the beginning of the ancient civilization the human race strives for methods to get energy from. Wind energy was one of the earliest energy sources have been used by the human being. It has been used in grinding the grain to flour, powering the sailboats and pumping the water from the deep wells. In the recent years the need for clean energy has been raised due to the Global Warming ofearth, therefore the wind energy has been introduced as a key player in the field of clean renewable energy and alternative to the fossil fuel in supplying the cities, factories ...etc. with the electrical power. The main idea is to convert the kinetic energy in the wind flowing to electrical power through the wind turbines. The wind turbine is the device that extracts the kinetic energy from the wind, the wind turbines design consists of rotor which harnesses the kinetic energy from the wind, the tower, gearbox and the generator. There are two main types of wind turbines according to the position of the axis of rotation of the wind turbine, one that rotates around the horizontal axis parallel to the ground which is more common horizontal axis wind turbine (HAWT) and the one which rotates around vertical axis to the ground vertical axis wind turbine (VAWT).Also there are two main types in VAWT wind turbines according to how the kinetic energy is extracted from the wind, first is the drag type like Savonius wind turbine and airfoil lift type like Darrieus wind turbine. Darrieus turbine

It is a type of VAWT, consists of 2 or 3 blades each have C-shape which cross section is airfoil, which form the eggbeater shape. This design was originally introduced by the French engineer Georges Jean Marie Darrieus 1931[4].Darrieus turbine is an airfoil lift type as the blades are rotating and airfoil moving forward the air creates angle of attack with blade and produce lift on the blade which helps to rotate the blades in the same direction therefore Darrieus turbine does not need yaw system and this is basic advantage for it, then the gearbox and generator can be housed on the ground. Disadvantages had discovered for the Darrieus turbine like low tip speed ratio, no self-starting capability and maintenance problems. Several alterations had been made to the design to counter these disadvantages one of these alterations is the H-rotor in which the curved rotor blades replaced by straight blades connected to the rotor shaft by struts.

\section{PURPOSE OF THE PRESENT WORK.}

Due to the growing threats of the Earth global warming and the fossil's fuel burning, many countries all over the world are increasing its activities in the field of the renewable energy year after year. Indeed, after all achievements in the field, the majority depend on the Horizontal axis turbines which is not suitable for the low wind speed condition and the urban areas. Vertical Axis Wind Turbines (VAWT) like Darrieus turbine is very promising in the mentioned conditions but it has some drawbacks, to recap, the main advantages are

- Simple design which means low setup cost.

- Compact size.

- Placing the electrical and mechanical components on ground level is available.

- No need for yaw mechanism 
On the other hand, major disadvantages are:

- Lower efficiency than horizontal axis turbines.

- The dilemma of self-starting.

- Stability enhancement guy wires may make the entire design is unattractive, especially in farming environment.

- For the standard design, the uncontrolled power output cause material fatigue and may cause resonance problems.

- Due to the Higher loads on the shaft and bearing than HAWT fracture and failure may occur to the shaft or the bearing.

Because of these disadvantages of the Darrieus wind turbine many modifications had been made to the original design to enhance the reliability and efficiency, one famous alteration is the H-rotor (2 blades or 3 blades) which have more advantages like:

- Straight blades instead of the curved blades.

- Able to receive the wind from any direction.

- The blades connected to the shaft by robust struts.

- Very low cost due to easy setup and maintain.

The present work aims to study numerically the effect of farming of 3 H-rotor each have 3 blades in equilateral triangle farm-like configuration on the each of them, comparing the final performance to one of them when it's alone in the field using Computational Fluid Dynamics.

\section{AERODYNAMICS OF THE MODEL.}

the speed ratio $(\lambda)$ is defined as the ratio between the tip blade speed $(\omega R)$ and the freestream wind velocity, so:

$$
\lambda=\frac{\omega R}{U}
$$

from the velocity triangle in fig. 1 the relation between the azimuth angle, the angle of attack $\alpha$ and the tip speed ratio $\lambda$ is as follows:

$$
\alpha=\tan ^{-1}\left\lceil\frac{\sin \theta}{\lambda+\cos \theta}\right\rfloor
$$

If the airflow has angle of attacka, airfoil will generate lift force $F_{L}$ normal to the free stream and drag force $F_{D}$ in the direction of the free stream. Forces resolved to the tangential force $F_{T}$ and the axial force $F N$ as shown in Fig.1, Instantaneously the tangential force $F_{T}$ is responsible for the torque and the power outputs of the $\mathrm{H}$ rotor.For Darrieus H-rotor of height $\mathrm{H}$, freestream speed $\mathrm{U}$, the torque and the power on the axis of Darrieus turbine as follows:

$$
\begin{aligned}
& c_{m}=\frac{T}{\frac{1}{2} \rho A R U^{2}} \\
& c_{p}=\frac{P}{\frac{1}{2} \rho A U^{3}}
\end{aligned}
$$

Where $c_{m}$ and $c_{p}$ are the torque coefficient and power coefficient respectively. 


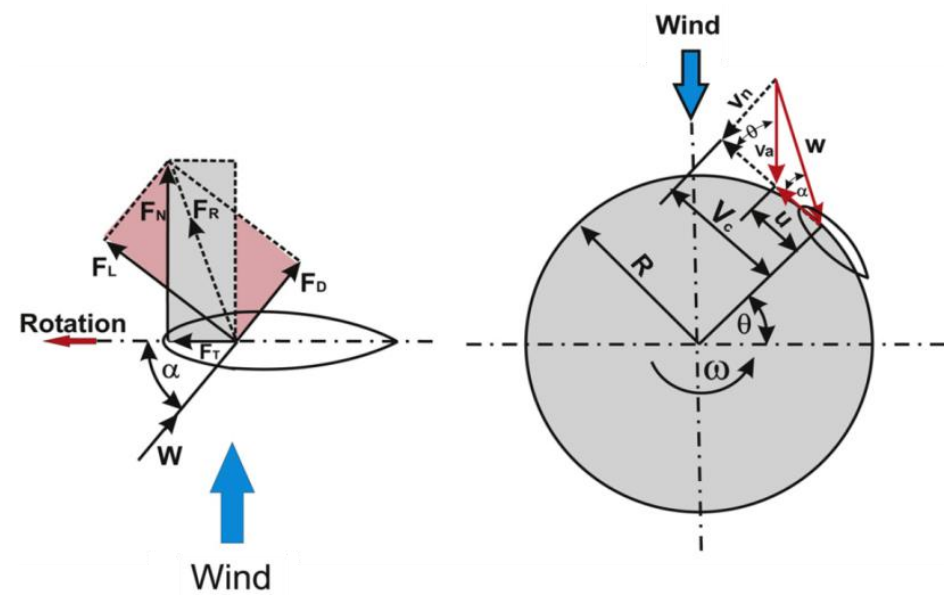

Figure1. Forces and Velocities distributions on Darrieus rotating airfoil [1, 2]

\section{NUMERICAL FLOW SIMULATION:}

Navier-Stokes equations formulated over a century ago governing the Newtonian's viscous fluid motion. The simplest way to solve a fluid dynamics problem is to solve Navier-Stokes equations with the proper boundary conditions.as we know the exact solution is for simple problems only and the usage of the supercomputers to get the exact solution for three-dimensional time-dependent turbulent flow is very expensive for money and timewise except for the simple cases at low Reynolds number. The Computational Fluid Dynamics (CFD) simulation for Darrieus Turbine is difficult because of high dependency nature of flow around the Darrieus blades[1]. ANSYS-Fluent ${ }^{\circledR} 16$ used along the whole study, it is well known software package that leads the industry of CFD simulation, because of the assumption and simplifications in the solution, the computational results deviate from the experimental results. So numerical model results must be validated.

\section{GEOMETRICAL CHARACTERISTICSOF VALIDATION MODEL}

The main geometrical features of the tested rotor are summarized in Table 1, constant wind speed of 9 $\mathrm{m} / \mathrm{s}$, the solidity parameter $\sigma \mathrm{s}$ is defined as $\mathrm{Nc} / 2 *$ Rrotor[1]. Rotor azimuthal position is identified by the angular coordinate of the center of pressure of blade No. 1 midsection, starting between the 2nd and 3rd Cartesian plane octants, as in Fig. 2[5].

\begin{tabular}{|l|l|}
\hline$D_{\text {rotor }}(\mathrm{mm})$ & 1030 \\
\hline $\mathrm{H}_{\text {rotor }}(\mathrm{mm})$ & $1(2 \mathrm{D}$ simulation $)$ \\
\hline $\mathrm{N}(-)$ & 3 \\
\hline Blade profile & NACA 0021 \\
\hline $\mathrm{c}(\mathrm{mm})$ & 85.8 \\
\hline Spoke-blade connection & $0.25 \mathrm{c}$ \\
\hline$\sigma$ & 0.25 \\
\hline Pressure $(\mathrm{pa})$ & 101325 \\
\hline
\end{tabular}

Table 1.validation model geometrical features [5, 6]

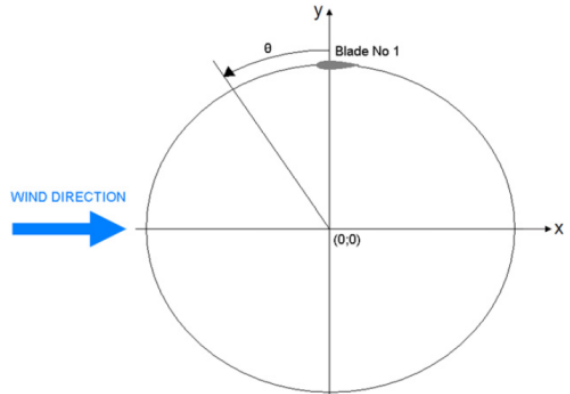

Figure 1. Azimuthal coordinate of blade midsection's center of pressure [5]. 


\section{COMPUTATIONAL FLUID DYNAMICS (CFD) SIMULATION.}

In the present work SOLIDWORKS ${ }^{\circledR} 2015$ as CAD software for drawing the models and exporting them to ANSYS ${ }^{\circledR} 16.0$ package that used for meshing in the Workbench and FLUENT® for Setting the boundary conditions and calculations.

The fig. shows the mesh for validation model built in ANSYS® 16.0 and the same
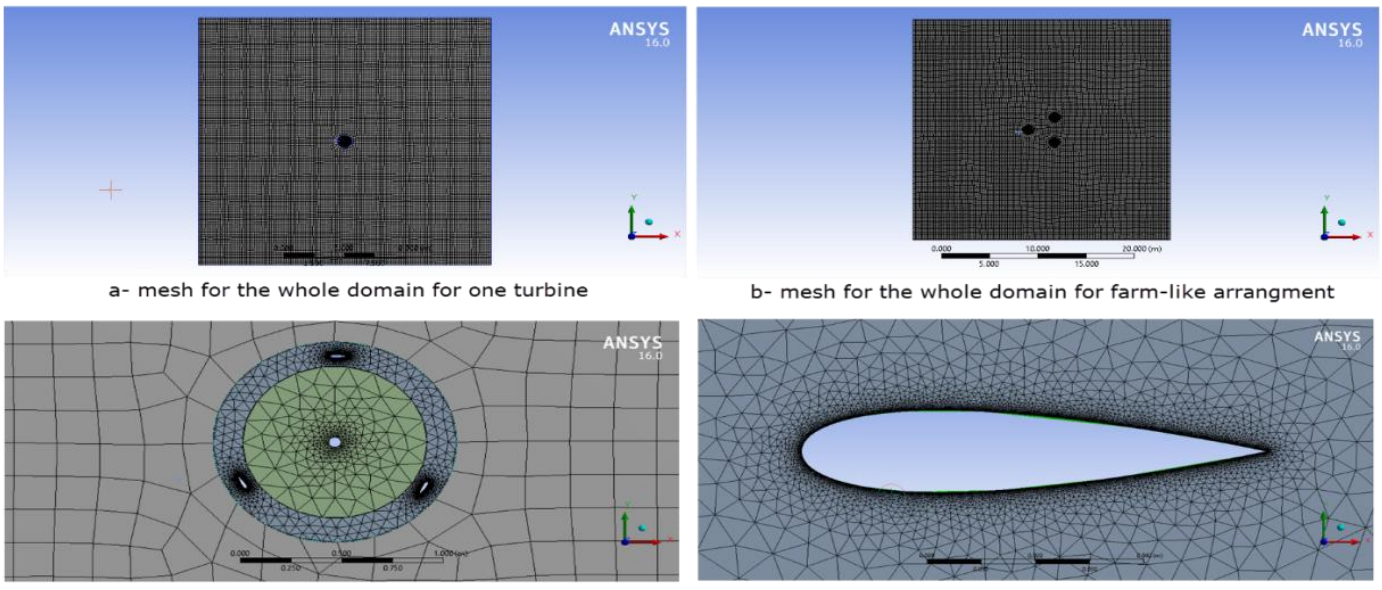

b- mesh for the whole domain for farm-like arrangment

c- mesh for the rotating ring

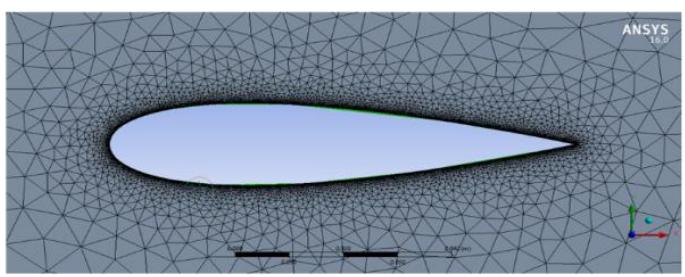

d- mesh for around the blade

Figure 2. Mesh Distribution around the VAWT Validation Model

The unsteady flow is solved by using the Sliding Mesh Model (SMM). using a constant time-step (0.001), four complete revolutions are always computed; the first one is used to initiate the correct flow solution and flow properties (in particular the torque coefficient $\mathrm{C}_{\mathrm{m}}$ ) are obtained by averaging the results during the last three revolutions[2]. On a standard PC, one evaluation (i.e., four revolutions for one specific configuration) takes about 660 min of computing time. Unsteady Reynolds-Averaged Navier-Stokes equations has been solved using the SIMPLE algorithm for pressure-velocity coupling[2, 3, 7]. Discretization has been performed Least Squared Cell Based gradient[7, 8], Standard pressure scheme[7]with Second-Order Upwind scheme for all variables and Second Order Implicit Transient Formulation[1-3, 9].

\section{COMPUTATIONAL DOMAIN AND MESH INDEPENDENCE STUDIES.}

The mesh size independence test had been performed for one geometrical configuration and several two dimensional unstructured meshes of increasing density and quality, ranging the mesh size from 17476 to 154504 cells are tested. The test shows that more than 88652 cells leads to a relative variation of the output below $5.2 \%$ as shown in fig. 4 , further calculations use the 88652 mesh size for sake of time and computation cost.

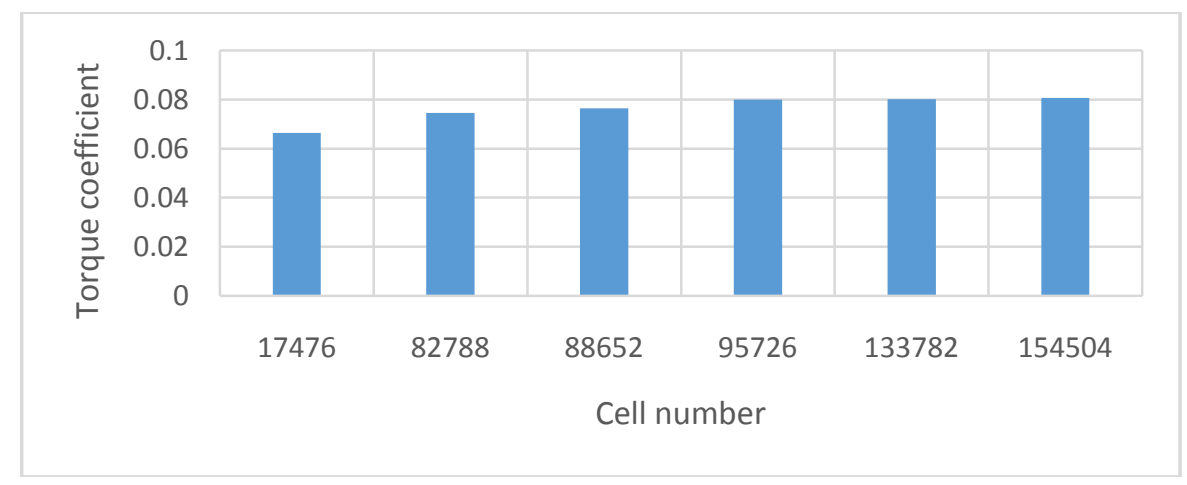

Figure 3. Mesh Independence range test

also the computational domain size has been investigated to ensure that the size of the domain doesn't effect on the results. A computational square domain of increasing dimensions (square domain, normalized by the rotor radius $\mathrm{R}$ as in Fig. 5. This demonstrates that the computational domain should extend at least over 20 times the rotor radius in each direction[3]. In a smaller domain, the boundary conditions effects on the results. 


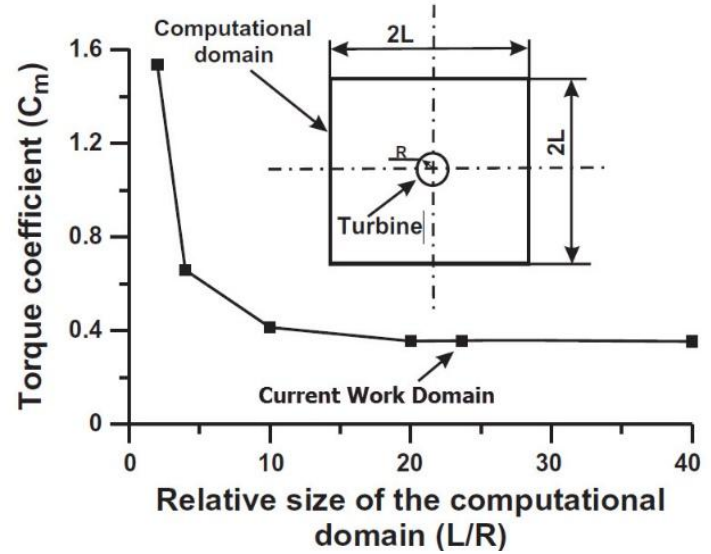

Figure 4 : Size of the computational domain and impact on the torque coefficient. [1, 3]

For the current work the $\mathrm{L} / \mathrm{R}=23.3$ was kept, which make a square of length 24 meters, that means 12 meter before and after the turbine as in Figure 6.

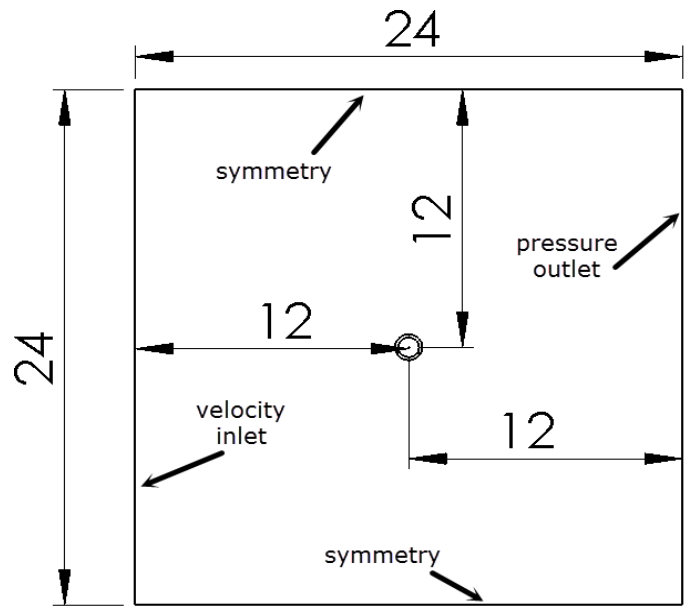

Figure 5 : Computational Domain Dimensions and Boundary Conditions for One Turbine

Also in the stage of the farm-like arrangement 12 meter kept before the first turbine's row and 12 meter after the second turbine's row as in figure 7.

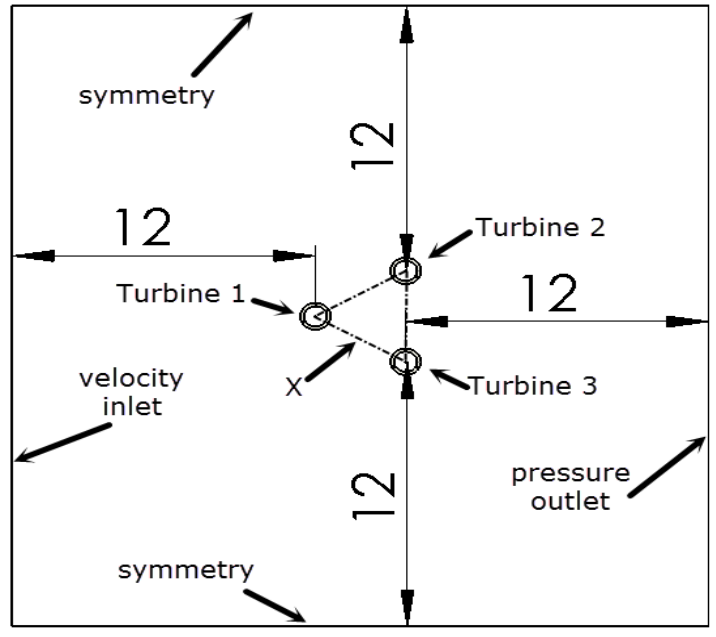

Figure 6 :Computational Domain Dimensions and Boundary Conditions for 3 Turbines Farm-Like Arrangement 
The detailed dimensions in meters and boundary conditions for the rotating ring in Figure 8.

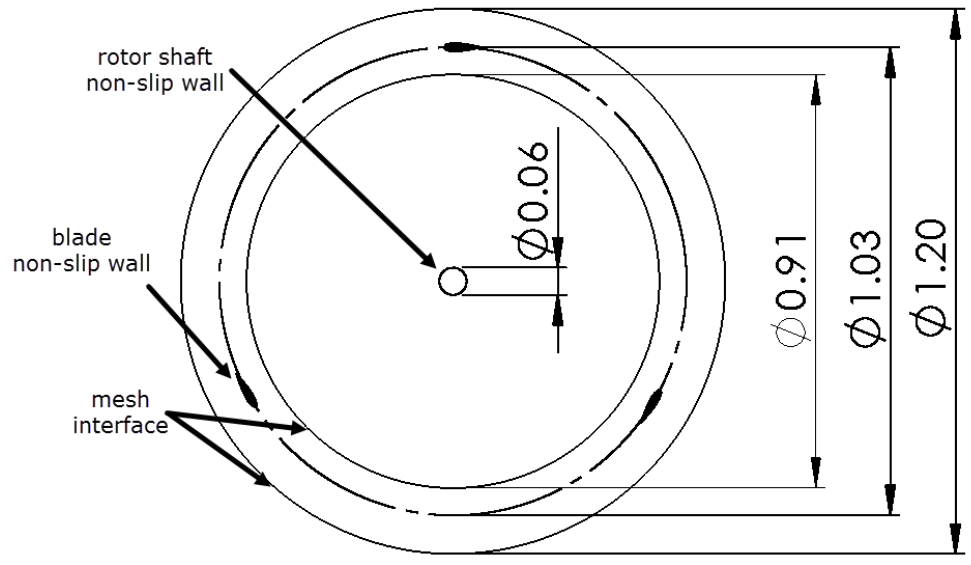

Figure 7 Dimensions and Boundary Conditions for The Rotating Ring

Turbulence Model Validation.

The validation comparison is done between the new model results and the published experimental and CFD results for an H-rotor Darrieus turbine[5] and M.H. Mohamed CFD results [2] as shown in Fig. 9

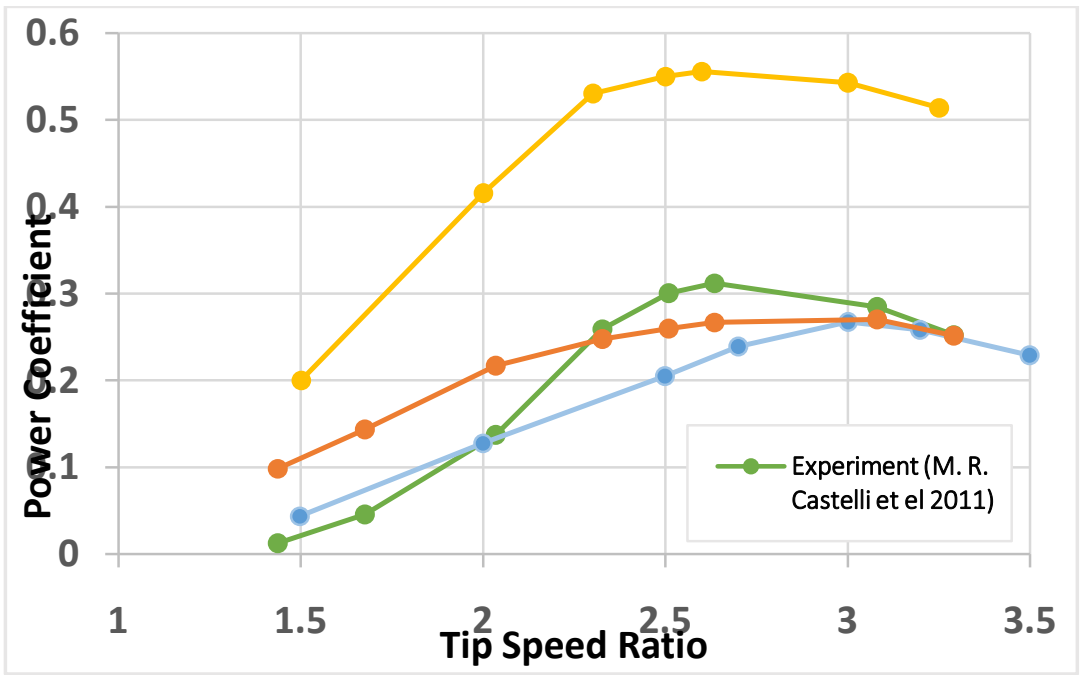

Figure 8 Validation of computational model, compared to published experimental and CFD results for a Darrieus turbine [2, 5]

Results indicates a good agreement between experiment and present CFD for the target function $\mathrm{C}_{\mathrm{p}}$ by using the realizable k-Eturbulence model, this model is usually recommended for the rotating bodies, the same criteria had been observed for other studies involving rotating blades and airfoils $[1,2]$. The realizable $k-\varepsilon$ turbulence model which was developed by Tsan-Hsing Shih et al. [10] has always been used in this study.This model contains a new formulation for the turbulent viscosity and a new transport equation for the dissipation rate $\varepsilon$. This model formulation ensures realizability and contains, as well, the effect of mean rotation on turbulence stresses[10]. it gives improved results for swirling flows and flows involving separation when compared to the standard k- $\varepsilon$ model. The near-wall treatment relies on Enhanced Wall functions. The y+values near all walls found not above 3.5 .

\section{DESIGN OF THE FARM-LIKE ARRANGEMENT}

To increase the allover power generated per unit area, the turbine's farm-like arrangement should be arranged on the minimum distance between each of them and the turbines don't deteriorate the performance of each other, the formation of the farm-like arrangement in this study was equilateral triangle.Theratio $\mathrm{X} / \mathrm{D}$ 
(where $\mathrm{x}$ is the distance between any of the turbines) is the dimensionless distance between the turbines, a range of $1.5 \mathrm{D}-20 \mathrm{D}$ had been tested at $\lambda=3.291$, all the settings and boundary conditions remain the same except five complete revolutions are always computed; the first two are used to initiate the correct flow solution and flow properties $(\mathrm{Cm})$ are obtained by averaging the last three revolutions because of increasing domain dimensions needed more time to initiate the correct solution. the results as shown in Fig. 8 shows that at $\mathrm{x} / \mathrm{D}=13$ the result of the three turbines became almost the same and have a good agreement to the validation model result which mean that the minimum distance between the turbines and don't affect negatively on the performance of any of them is $13 \mathrm{D}$.

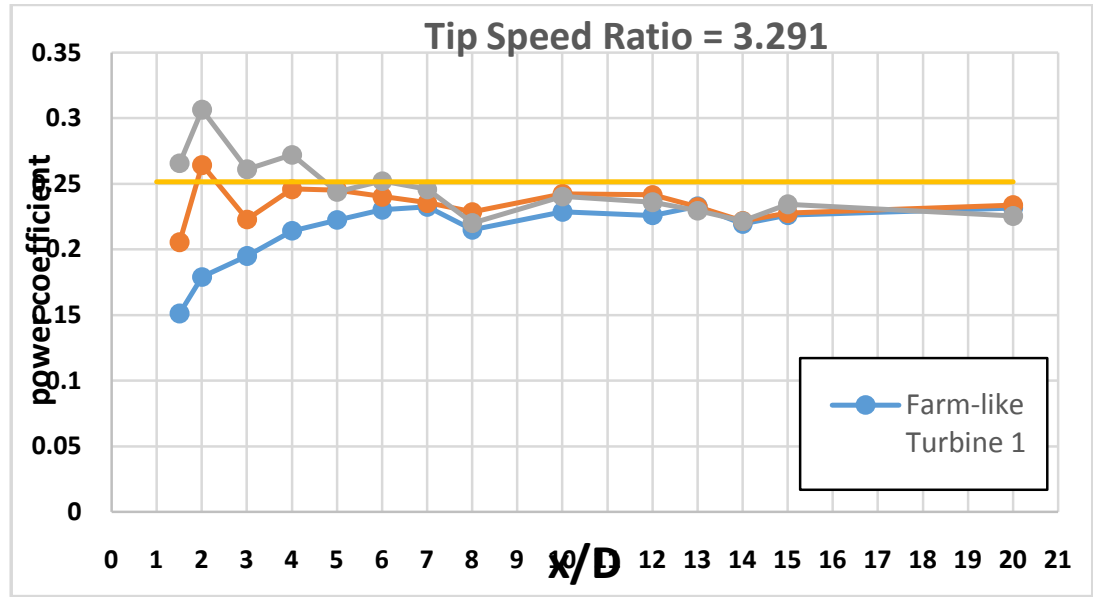

Figure 9: farm-like arrangement results for the three turbines.

For each lamda of the 13D case give us the curve shown in Fig. 11

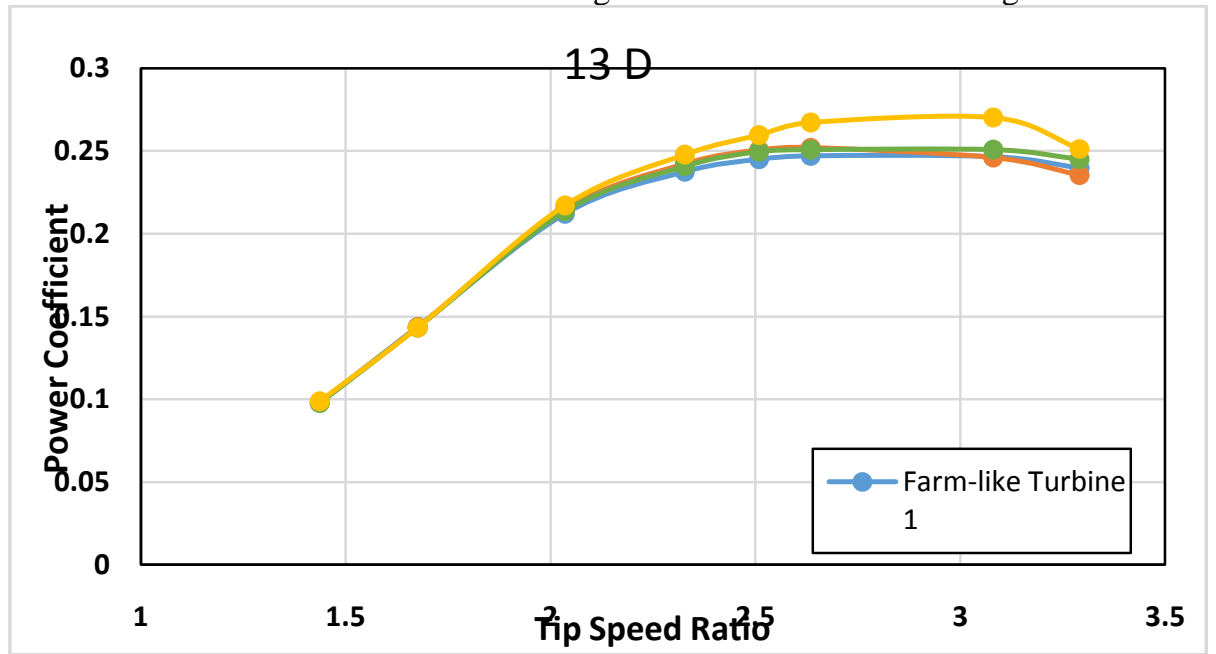

Figure 10. 13D results comparison between farm-like arrangement and single turbine

from which we can say there enough agreement between the present work for 1 turbine and 13D configuration showing small effect on the performance on each of the 3 turbines. these results show also almost identical performance for the three turbines all-over the tip speed ratio range.

\section{CONCLUSION AND FUTURE WORK.}

Farm-like arrangement optimization is crucial for the practical implementation and spread of the VAWT on large scale either in urban areas, desert or offshore sites. such that it is essential to get the optimal distance between the consecutive turbines which in the current work is $13 \mathrm{D}$, that means from 13D and onwards there is no significant effect on the performance of each turbine occurred from neighboring turbines. 
In the future acoustics calculations will be conducted because it is essential if implementation in urban areas is considered because of great effect of the noise on the residents. Also I will study the effect a rod-like air-flow intruder in front of the turbines with certain distance on enhancing the overall wind turbine performance.

\section{REFERENCES}

[1] M. H. Mohamed, "Impacts of solidity and hybrid system in small wind turbines performance," Energy, vol. 57, pp. 495-504, 8/1/ 2013.

[2] M. H. Mohamed, "Performance investigation of H-rotor Darrieus turbine with new airfoil shapes," Energy, vol. 47, pp. 522-530, 11// 2012.

[3] M. H. Mohamed, G. Janiga, E. Pap, and D. Thévenin, "Optimal blade shape of a modified Savonius turbine using an obstacle shielding the returning blade," Energy Conversion and Management, vol. 52, pp. 236-242, 1// 2011.

[4] T. J. Price, "UK large-scale wind power programme from 1970 to 1990: the Carmarthen Bay experiments and the musgrove vertical-axis turbines," Wind Engineering, vol. 30, pp. 225-242, 2006.

[5] M. R. Castelli, A. Englaro, and E. Benini, "The Darrieus wind turbine: Proposal for a new performance prediction model based on CFD," Energy, vol. 36, pp. 4919-4934, 2011.

[6] M. R. Castelli, G. Ardizzon, L. Battisti, E. Benini, and G. Pavesi, "Modeling strategy and numerical validation for a Darrieus vertical axis micro-wind turbine," in ASME 2010 International Mechanical Engineering Congress and Exposition, 2010, pp. 409-418.

[7] T. G. Abu-El-Yazied, H. N. Doghiem, A. M. Ali, and I. M. Hassan, "Investigation of the Aerodynamic Performance of Darrieus Vertical Axis Wind Turbine," IOSR Journal of Engineering, vol. 4, pp. 18-29, 2014.

[8] R. Lanzafame, S. Mauro, and M. Messina, "2D CFD modeling of H-Darrieus wind turbines using a transition turbulence model," Energy Procedia, vol. 45, pp. 131-140, 2014.

[9] Y. Chen and Y. Lian, "Numerical investigation of vortex dynamics in an H-rotor vertical axis wind turbine," Engineering Applications of Computational Fluid Mechanics, vol. 9, pp. 21-32, 2015.

[10] T.-H. Shih, W. W. Liou, A. Shabbir, Z. Yang, and J. Zhu, "A new k- $\epsilon$ eddy viscosity model for high reynolds number turbulent flows," Computers \& Fluids, vol. 24, pp. 227-238, 3// 1995.

Glossary

A: area of rotor $(\mathrm{DH}), \mathrm{m} 2$

Cp: power coefficient $\left(\mathrm{P} /\left[1 / 2^{\rho}\right.\right.$ AU3])

$\mathrm{Cm}$ : torque coefficient (T/ [ $\left.\left.{ }^{\rho} \mathrm{R} 2 \mathrm{HU} 2\right]\right)$

c: blade chord, $\mathrm{m}$

D: turbine diameter (2R), $m$

FL: lift force, $\mathrm{N}$

FD: drag force, $\mathrm{N}$

FT: tangential force, $\mathrm{N}$

FN: axial force, $\mathrm{N}$

FR: resultant force, $\mathrm{N}$

$\mathrm{H}$ : blade height, $\mathrm{m}$

$\mathrm{N}$ : rotational speed of rotor, rpm

$\mathrm{n}$ : number of blades

$\mathrm{R}$ : radius of turbine, $\mathrm{m}$

$\mathrm{T}$ : output torque, $\mathrm{Nm}$

$\mathrm{U}$ : mean wind velocity in axial direction, $\mathrm{m} / \mathrm{s}$

$\mathrm{u}$ : peripheral velocity of the blade, $\mathrm{m} / \mathrm{s}$

a: angle of attack, (o)

$\mathrm{X}$ : the side length of the triangle $(\mathrm{m})$

$\mathrm{s}$ : solidity, (nc/2R)

$\lambda$ : speed ratio, $(\omega R / U)$

r: density, $\mathrm{kg} / \mathrm{m} 3$

$\theta$ : azimuth angle, (o)

$\omega$ : angular speed, $1 / \mathrm{s}$ 